\title{
Short communication: Norbixin and bixin partitioning in Cheddar cheese and whey
}

\author{
T. J. Smith, X. E. Li, and M. A. Drake ${ }^{1}$ \\ Department of Food, Bioprocessing and Nutrition Sciences, Southeast Dairy Foods Research Center, North Carolina State University, \\ Raleigh 27695
}

\section{ABSTRACT}

The Cheddar cheese colorant annatto is present in whey and must be removed by bleaching. Chemical bleaching negatively affects the flavor of dried whey ingredients, which has established a need for a better understanding of the primary colorant in annatto, norbixin, along with cheese color alternatives. The objective of this study was to determine norbixin partitioning in cheese and whey from full-fat and fatfree Cheddar cheese and to determine the viability of bixin, the nonpolar form of norbixin, as an alternative Cheddar cheese colorant. Full-fat and fat-free Cheddar cheeses and wheys were manufactured from colored pasteurized milk. Three norbixin $(4 \% \mathrm{wt} / \mathrm{vol})$ levels (7.5, 15 , and $30 \mathrm{~mL}$ of annatto/454 $\mathrm{kg}$ of milk) were used for full-fat Cheddar cheese manufacture, and 1 norbixin level was evaluated in fat-free Cheddar cheese (15 mL of annatto/454 kg of milk). For bixin incorporation, pasteurized whole milk was cooled to $55^{\circ} \mathrm{C}$, and then $60 \mathrm{~mL}$ of bixin/454 kg of milk (3.8\% wt/vol bixin) was added and the milk homogenized (single stage, 8 $\mathrm{MPa}$ ). Milk with no colorant and milk with norbixin at $15 \mathrm{~mL} / 454 \mathrm{~kg}$ of milk were processed analogously as controls. No difference was found between the norbixin partition levels of full-fat and fat-free cheese and whey (cheese mean: $79 \%$, whey: $11.2 \%$ ). In contrast to norbixin recovery (9.3\% in whey, $80 \%$ in cheese), $1.3 \%$ of added bixin to cheese milk was recovered in the homogenized, unseparated cheese whey, concurrent with higher recoveries of bixin in cheese (94.5\%). These results indicate that fat content has no effect on norbixin binding or entrapment in Cheddar cheese and that bixin may be a viable alternative colorant to norbixin in the dairy industry.

Key words: annatto, norbixin, bixin, whey, cheese

Received October 16, 2013.

Accepted February 14, 2014.

${ }^{1}$ Corresponding author: maryanne_drake@ncsu.edu

\section{Short Communication}

In the United States, a large majority of dried whey protein is manufactured from Cheddar cheese whey colored with annatto, a coloring agent extracted from the seed of the Bixa orellana shrub (Scotter, 2009). The major carotenoids responsible for the yellow color of annatto are norbixin and bixin, although the watersoluble form, norbixin, is the primary carotenoid used in cheese manufacture (Giuliano et al., 2003; Kang et al., 2010), where it is added directly to cheese milk.

Norbixin itself has no direct effect on the flavor of dried whey protein concentrate (WPC; Campbell et al., 2010), but it must be removed from fluid whey to produce a desirable white spray-dried product. Currently, benzoyl peroxide and hydrogen peroxide are the only 2 chemical bleaching agents approved by the US Food and Drug Administration (FDA) for bleaching of whey (US FDA, 2011a,b). The use of chemical bleaching agents has many detrimental effects, including off-flavor development, chemical residues, and changes in whey protein functional properties (Listiyani et al., 2011; Jervis et al., 2012).

Off-flavor development in WPC due to lipid oxidation is of special concern when dealing with oxidative chemical bleaching agents. Aldehydes are primarily responsible for off-flavors in dried whey proteins (Carunchia Whetstine et al., 2003; Wright et al., 2009; Whitson et al., 2010). Common off-flavors caused by lipid oxidation products in WPC are cardboard, cabbage, and fatty-oxidized flavors (Whitson et al., 2010; Listiyani et al., 2011). Investigating a method to reduce or eliminate unnecessary and harsh processing steps such as bleaching is important to add overall value to whey ingredients. Many studies have been conducted on the effects of whey processing on whey protein flavor and bleaching efficacy (Croissant et al., 2009; Campbell et al., 2010; Listiyani et al., 2011, 2012; Jervis et al., 2012) but, to our knowledge, a study of norbixin partitioning and partitioning differences between cheeses and wheys with differing fat levels has not been performed. Specific knowledge on norbixin partitioning will enable development of optimal bleaching conditions or alterna- 
tive bleaching approaches. Bixin is the nonpolar form of annatto and is a dicarboxylic monomethyl ester apocarotenoid (Bouvier et al., 2003), and can be found in cis $(\alpha)$ and trans $(\beta)$ forms due to geometrical isomerism around the 5,6-carbon atoms (Lancaster and Lawrence, 1995). Because of its nonpolar nature, bixin has been used to color high-fat dairy products such as butter (Lancaster and Lawrence, 1995). To our knowledge, no studies have evaluated bixin as a natural colorant for Cheddar cheese.

Relatively little is known of the partitioning and binding characteristics of norbixin during the cheese making process. Previous studies have postulated that approximately $20 \%$ of the norbixin added during the cheese making process partitioned into the whey, but little research has been performed in the past $30 \mathrm{yr}$ that supports this hypothesis (Barnicoat, 1950; Chapman et al., 1980). Although it is often assumed that norbixin is contained within the serum phase of the whey, it is also thought that it may be bound to the retinol-binding site of $\beta$-LG or with other whey proteins or whey components (Govindarajan and Morris, 1973; Hammond et al., 1975; Cho et al., 1994; Zhu and Damodaran, 2012). Recently, it has been hypothesized that norbixin exists as a micelle and associates with the milk fat globule membrane portion of whey (Zhu and Damodaran, 2012). The objectives of this study were to investigate norbixin partitioning into cheese and liquid whey using modern methods and instrumentation to better understand norbixin behavior during the cheese making process and to investigate the viability of bixin as an alternative cheese coloring agent.

\section{Experimental Overview}

Two sets of experiments were performed in this study. The first was an experiment with both full-fat and fatfree cheeses using norbixin as a colorant. The purpose of this experiment was to determine partitioning of norbixin between cheese and whey when differing amounts of annatto were added to cheese milk and to determine if differences existed between norbixin content in cheese and whey from fat-free and full-fat cheeses. Three sets of Cheddar cheese were produced using whole pasteurized milk with 3 levels of added annatto $(7.5,15$, and $30 \mathrm{~mL} / 454 \mathrm{~kg}$ of milk). Fat-free Cheddar cheese was manufactured from pasteurized, fat-separated skim milk with $15 \mathrm{~mL}$ of annatto/454 $\mathrm{kg}$ of milk added (Scotter et al., 2002; Nair et al., 2004; Campbell et al., 2010). Samples taken for norbixin extraction and measurement included milk after addition of annatto, Cheddar cheese, and unseparated, unpasteurized whey. Four trials of all 4 cheeses were conducted.
The second experiment was conducted to establish the incorporation of bixin into cheese milk and then to compare partitioning of bixin and norbixin in cheese and whey. This was a proof-of-concept study to determine if bixin would have a different partition between whey and cheese compared with norbixin. Again, 3 sets of Cheddar cheese (no color, norbixin at $15 \mathrm{~mL} / 454 \mathrm{~kg}$ of milk, bixin at $60 \mathrm{~mL} / 454 \mathrm{~kg}$ of milk) were produced in quadruplicate. Because of the nonpolar nature of bixin, homogenization of the cheesemilk containing bixin was necessary before cheese manufacture. Samples taken for bixin extraction matched those taken for experiment 1 .

\section{Manufacture of Cheddar Cheese and Liquid Whey with Norbixin}

Raw whole milk, $98 \mathrm{~kg}$, was obtained from the North Carolina State University Dairy Research and Education Farm (Raleigh). Milk was vat pasteurized (model MPD1050, Micro Process Design, D\&F Equipment Co., McLeansville, NC) at $63^{\circ} \mathrm{C}$ for 30 min. After pasteurization, milk was immediately cooled to $31^{\circ} \mathrm{C}$ and inoculated with freeze-dried lactic acid starter culture [50 direct culture units (DCU) $/ 454 \mathrm{~kg}$, Choozit MA 11, Danisco, New Century, NJ] and Cheddar cheese manufacture proceeded as described by Campbell et al. (2012). Whey was drained from curds at $\mathrm{pH}$ 6.40. The fat-free cheese make procedure was identical except that after pasteurization, hot milk was separated in a hot bowl separator (model JF 125 EAR, Clair, Althofen, Austria) to produce skim milk and cream. The separated skim milk was then immediately cooled to $31^{\circ} \mathrm{C}$ and inoculated with freeze-dried lactic acid starter culture. Remaining cheese make steps were identical to those performed with the full-fat cheese make.

For all cheeses, once a $\mathrm{pH}$ of 6.40 was reached, whey was drained and strained to remove cheese particles, and $1 \mathrm{~L}$ was taken for analysis. The cheddaring methods were modified from Nair et al. (2004). During cheddaring, trenched curd loaves were turned every 20 min to a final $\mathrm{pH}$ of 5.2 before milling. Curd was milled manually with knives and salted (2.7\% salt wt/ wt, based on curd weight). Salted milled curds were pressed for $16 \mathrm{~h}$ at $2.8 \mathrm{~kg} / \mathrm{cm}^{2}$ (40 psi), vacuum sealed, and stored at $4^{\circ} \mathrm{C}$.

\section{Manufacture of Cheddar Cheese and Liquid Whey with Bixin}

For experiment 2, to compare partitioning of bixin and norbixin in cheese and whey, the same starting concentrations of bixin and norbixin in homogenized cheese milk were required. The norbixin cheese milk 
was also homogenized to create the same experimental conditions for both bixin and norbixin and to prove that homogenization was not a source of decreased bixin partitioning in liquid whey. Because of the nonpolar nature of bixin, colorant loss occurred during milk homogenization; therefore, preliminary experiments were conducted to determine the initial added concentration of bixin to milk that yielded a final (posthomogenization) bixin concentration most similar to the final (post-homogenization) norbixin concentration of cheese milk $(P>0.05)$. Preliminary studies were also conducted to determine the lowest homogenization pressure required to stabilize a bixin suspension in milk. Bixin (3.8\% wt/vol bixin, Chr. Hansen Inc., Milwaukee, WI) at $15 \mathrm{~mL} / 454 \mathrm{~kg}, 30 \mathrm{~mL} / 454 \mathrm{~kg}, 45 \mathrm{~mL} / 454 \mathrm{~kg}$, and $60 \mathrm{~mL} / 454 \mathrm{~kg}$, and norbixin $(4 \% \mathrm{wt} /$ vol norbixin, Dairy Connection Inc., Madison, WI) at $15 \mathrm{~mL} / 454 \mathrm{~kg}$ (norbixin concentration for standard Cheddar cheese production, Campbell et al., 2010, 2012) was added to $1 \mathrm{~L}$ of milk separately and then fed immediately into a homogenizer (Panda 2K, Niro Inc., Columbia, $\mathrm{MD}$ ) with 2 passes at $8 \mathrm{MPa}$ (single stage) at $55^{\circ} \mathrm{C}$ for each sample. Preliminary studies established that $8 \mathrm{MPa}$ was the lowest pressure that resulted in stable dispersion of bixin into milk, where there was no visual separation of bixin and milk after homogenization and the subsequent $4 \mathrm{~h}$ at $21^{\circ} \mathrm{C}$. The minimum homogenization pressure was determined to minimize the effect of homogenization on cheese texture. Addition of $60 \mathrm{~mL}$ of bixin per $454 \mathrm{~kg}$ of milk before homogenization resulted in a bixin concentration in cheese milk that was not significantly different from the colorant concentration of the homogenized cheese milk with norbixin (15 $\mathrm{mL}$ of annatto solution/454 $\mathrm{kg}$ of milk; $P>0.05$ ). All preliminary experiments were performed in duplicate.

Cheddar cheese was manufactured from whole milk with no colorant and whole milk with $15 \mathrm{~mL}$ of norbixin $/ 454 \mathrm{~kg}$ as controls. Cheddar cheese made from whole milk with $60 \mathrm{~mL}$ of bixin/454 $\mathrm{kg}$ (followed by homogenization at $8 \mathrm{MPa}$ ) was also manufactured. The milks of all 3 treatments were homogenized to create the same experimental conditions. For each treatment, whole raw bovine milk was obtained from the North Carolina State University Dairy Education Unit (Raleigh) and batch pasteurized at $63^{\circ} \mathrm{C}$ for $30 \mathrm{~min}$. Pasteurized milk was cooled to $55^{\circ} \mathrm{C}$ before homogenization. All cheeses were manufactured using the method described in Experiment 1 except that only $4 \mathrm{~kg}$ of milk was used for each treatment due to limitations caused by the need to homogenize the milk to incorporate bixin. The curd was then pressed at $36.3 \mathrm{~kg}$ for $16 \mathrm{~h}$ (Cheese Press E28, New England Cheesemaking Supply Company, South Deerfield, MA). This experiment was replicated in quadruplicate.

\section{Norbixin and Bixin Extraction and Quantification}

The annatto solution used to color the cheeses in all experiments was diluted 1:100,000 (wt/vol) in 3:7 glacial acetic acid:methanol (wt/vol) and injected onto the HPLC, as described by $\mathrm{Li}$ et al. (2012) to determine norbixin concentration. The norbixin and bixin extraction methods were modified and adapted from the method described by Campbell et al. (2012). Two milliliters of colored milk, $6 \mathrm{~mL}$ of liquid whey, or $1 \mathrm{~g}$ of grated cheese was weighed into a $50-\mathrm{mL}$ centrifuge tube. Three milliliters of ethanol $(99.5 \% \mathrm{vol} / \mathrm{vol}$, EMD Chemicals, Gibbstown, NJ), $3 \mathrm{~mL}$ of chloroform (EMD Chemicals), and $1 \mathrm{~mL}$ of $1 \%$ acetic acid (99.5\% vol/vol, J. T. Baker, Phillipsburg, NJ) were added and vortexed sequentially. After centrifugation at $11,952 \times g$ for 10 min at $4^{\circ} \mathrm{C}$, the bottom layer was collected and the volume measured. The bottom layer was then transferred to a solid-phase extraction column (SPE; Strata-NH2 SPE column, $500 \mathrm{mg} / 3 \mathrm{~mL}$, Phenomenex, Torrance, CA). Four milliliters of $n$-hexane (EMD Chemicals), $2.5 \mathrm{~mL}$ of $n$-hexane:diethyl ether (1:1 vol/vol; EMD Chemicals), and $1 \mathrm{~mL}$ of acetone (EMD Chemicals) were used to condition the SPE column. Then, the norbixin or bixin was eluted with $2 \mathrm{~mL}$ of methanol:glacial acetic acid (7:3 vol/vol) into amber vials (VWR International, ) and placed in an autosampler (Waters 2707 Autosampler) at $4^{\circ} \mathrm{C}$ until injection. The final product volume was measured and then injected $(15 \mu \mathrm{L})$ onto the HPLC (Waters 1525 Binary Pump, Waters, Milford, MA) equipped with a C18 column (Phenomenex Kinetex $2.6 \mu \mathrm{m}, 100 \times 4.6 \mathrm{~mm}, 40^{\circ} \mathrm{C}$; Campbell et al., 2012). A 7-point standard curve of norbixin was generated from 0 to $10 \mathrm{mg} / \mathrm{kg}$ norbixin $(45 \% \mathrm{wt} / \mathrm{wt}$, Chr. Hansen Inc.) as previously described (Campbell et al., 2012). An 11-point standard curve was generated for bixin (90\% wt/wt, Chr. Hansen Inc.) from 0 to $5 \mathrm{mg} /$ $\mathrm{kg}$. The bixin powder $(0.05 \mathrm{~g})$ was dissolved in $3 \mathrm{~mL}$ of dimethylformamide (VWR International, Radnor, PA) and brought to volume with acetonitrile (VWR International). The stock solution was then diluted in 7:3 methanol:glacial acetic acid to make the standard curve. The concentrations of norbixin and bixin in milk, unseparated whey, separated whey, and cheese were calculated based on absorption and standard curves.

\section{Mass Balance of Bixin or Norbixin}

A mass balance of norbixin in the full-fat and fatfree milk, cheese, and whey and the bixin in the homogenized milk, cheese, and whey was performed. For experiments 1 and 2, the weight of the whole or skim milk and weight of the cheese was recorded. The weight of the whey portion was extrapolated by subtracting 
the final weight of the cheese from the total weight of the milk. The mass balance of the system is given by

$$
\mathrm{M}_{\text {nor }}=\left(\mathrm{CV}_{\text {post }} \mathrm{V}_{\text {tpre }} \mathrm{M}_{\text {tot }}\right) /\left(\mathrm{V}_{\text {cpre }} \mathrm{M}_{\mathrm{s}}\right),
$$

where $\mathrm{M}_{\text {nor }}$ is the total mass $(\mu \mathrm{g})$ of bixin or norbixin in the milk, cheese, or whey, respectively; $\mathrm{C}$ is the bixin or norbixin concentration $(\mu \mathrm{g} / \mathrm{L})$ of the SPE solution injected onto the HPLC; $\mathrm{V}_{\text {post }}$ is the total volume (L) of the SPE solution injected onto the HPLC; $\mathrm{V}_{\text {tpre }}$ is the total volume $(\mathrm{L})$ of the extract solution preplacement onto the SPE column; $\mathrm{M}_{\text {tot }}$ is the total mass $(\mathrm{kg})$ of milk, whey, or cheese used in the cheese make procedure; $\mathrm{V}_{\text {cpre }}$ is the volume $(\mathrm{L})$ of the extract solution (pre-SPE) placed onto the SPE column; and $\mathrm{M}_{\mathrm{s}}$ is the mass of the sample of milk, whey, or cheese from which the norbixin is extracted.

Using the previous equation, the mass of bixin or norbixin in milk was calculated. The relative difference between the calculated mass of bixin or norbixin in milk found through the extraction procedure, and the actual amount of bixin or norbixin added to milk provided the extraction efficiency. Extraction efficiency was determined by the following equation:

$$
\mathrm{E}=\left(\mathrm{M}_{\mathrm{ann}}\right) 100 / \mathrm{M}_{\text {nor }},
$$

where $\mathrm{E}$ was percentage extraction efficiency, $\mathrm{M}_{\mathrm{ann}}$ was the mass $(\mu \mathrm{g})$ of bixin or norbixin added to the milk, and $\mathrm{M}_{\text {nor }}$ was the mass $(\mathrm{mg})$ of norbixin calculated to be in the milk through the extraction procedure.

Correcting for extraction efficiency allowed us to determine true norbixin loss during the cheese make procedure. It was also important to know if differences in norbixin addition or fat content, as determined by experiments 1 and 2, had an effect on the amount of norbixin lost during the cheese make procedure. Bixin and norbixin are sensitive to both heat and light, both of which occur during cheese manufacture; as such, a modest amount of bixin or norbixin destruction during cheese manufacture was expected (de Oliveira and Rodriguez-Amaya, 2007). Percentage norbixin loss was determined by the following equation:

$$
\mathrm{L}=\mathrm{M}_{\mathrm{ann}}-\left[\left(\mathrm{M}_{\mathrm{wnor}}+\mathrm{M}_{\mathrm{cnor}}\right) 100 / \mathrm{E}\right],
$$

where $\mathrm{L}$ was percentage norbixin loss, $\mathrm{M}_{\mathrm{ann}}$ was the mass $(\mu \mathrm{g})$ of bixin or norbixin added to the milk, $\mathrm{M}_{\text {wnor }}$ was the total mass $(\mu \mathrm{g})$ of bixin or norbixin in whey, $\mathrm{M}_{\text {cnor }}$ was the total mass $(\mu \mathrm{g})$ of bixin or norbixin in the cheese, and $\mathrm{E}$ was the percentage extraction efficiency. Using the percentage bixin or norbixin loss during the procedure, the mass of the bixin or norbixin lost was determined using the following equation:

$$
\mathrm{M}_{\mathrm{lnor}}=\mathrm{LM}_{\mathrm{ann}}
$$

where $\mathrm{M}_{\text {lnor }}$ was the mass $(\mu \mathrm{g})$ of bixin or norbixin lost, $\mathrm{L}$ was the percentage bixin or norbixin lost, and $\mathrm{M}_{\mathrm{ann}}$ was the mass $(\mu \mathrm{g})$ of total bixin or norbixin added to the milk.

\section{Proximate Analysis}

Proximate analysis (solids, total N, and fat) of liquid whey and full-fat and fat-free cheese were calculated using standard methods (Nelson and Barbano, 2004). Mineral analysis of the full-fat and fat free cheeses (phosphorus and sodium) was performed in duplicate as described by Lloyd et al. (2009). Sodium chloride in the cheese was determined using a salt analyzer (SAT500, DKK-TOA Corp., Tokyo, Japan).

\section{Hunter Color ( $L * a * b *)$}

The color of milks, liquid wheys, and cheeses were measured using a Minolta Chroma meter (CR-410, Minolta, Ramsey, NJ). Each cheese sample was measured directly in duplicate. For liquid samples, $10 \mathrm{~mL}$ of each sample was placed into a $60 \mathrm{~mm} \times 15 \mathrm{~mm}$ polystyrene Petri dish in duplicate (Becton Dickinson, Franklin Lakes, NJ); each Petri dish was measured in duplicate as well.

\section{Statistical Analysis}

Data were analyzed by ANOVA with means separation (XLSTAT, version 2011.5.01; Addinsoft, New York, NY). Differences between the sample means were analyzed by Tukey's honestly significant difference (HSD).

\section{Proximate Analysis}

In experiment 1 , the composition of the whole milk was consistent $(P>0.05)$. Fat averaged $3.70 \pm 0.25 \%$ (wt/wt) and solids averaged $12.03 \pm 0.26 \%$ (wt/wt). In liquid whey from whole milk, fat averaged $0.26 \pm$ $0.06 \%$ (wt/wt) and solids $6.61 \pm 0.17 \%$ (wt/wt; $P>$ 0.05). In full-fat Cheddar cheeses, fat averaged 33.51 $\pm 2.20 \%$ and solids $63.57 \pm 1.74 \%(P>0.05)$. Sodium chloride in the cheese was $1.35 \pm 0.09 \%$ (wet weight). Fat content of fat-free cheese, milk, and whey were at levels below the requisite $0.5 \mathrm{~g} /$ serving necessary to be considered "fat free" by the Code of Federal Regulations (US FDA, 2011c). The composition of the fat-free milk averaged $0.13 \pm 0.08 \%$ (wt/wt) fat and $8.98 \pm$ $0.20 \%$ (wt/wt) solids $(P>0.05)$. The composition of the whey from the fat-free Cheddar cheese averaged 
$0.03 \pm 0.02 \%(\mathrm{wt} / \mathrm{wt})$ fat and $6.54 \pm 0.08 \%$ (wt/wt) solids $(P>0.05)$. In fat-free Cheddar cheese, fat averaged $2.84 \pm 0.78 \%$ and solids $54.79 \pm 2.2 \%$. Sodium chloride in the cheese was $1.62 \pm 0.11 \%$ (wet weight).

In experiment 2 , the compositions of milks were not different from each other $(P>0.05): 12.98 \pm 0.08 \%$ (wt/wt) solids and $4.27 \pm 0.14 \%$ (wt/wt) fat. Liquid whey from whole milk averaged $6.64 \pm 0.09 \%$ (wt/wt) solids and $0.17 \pm 0.03 \%$ (wt/wt) fat. The compositions of the separated wheys for all 3 treatments were not distinct: $6.09 \pm 0.23 \%$ (wt/wt) solids and $0.01 \pm$ $0.007 \%$ (wt/wt) fat. The compositions of the cheese for all 3 treatments were not distinct: $65.62 \pm 1.70 \%$ (wt/ wt) solids and $33.71 \pm 1.75 \%$ (wt/wt) fat.

\section{Mass Balance of Norbixin and Bixin in Whey and Cheese}

For experiment 1, overall average norbixin extraction efficiency was $89 \%$ and was not affected by norbixin concentration or milk fat content (Table $1 ; P>0.05$ ). This efficiency was comparable to that reported by Bareth et al. (2002), who reported a recovery of $91.0 \% \pm$ $2.4 \%$ norbixin from Cheddar cheese. Loss in efficiency is likely due to several factors, including human error, incomplete solvent separation of norbixin from sample, and SPE column inefficiency. The purpose of extracting norbixin from the milk after addition of annatto was to find the extraction efficiency and correct for error caused by lack thereof. The milk after addition of annatto was used to determine the overall extraction efficiency for each individual trial due to its unadulterated state, whereas both cheese and whey go through periods of $\mathrm{pH}$ change, mechanical work, and heat and light exposure.

With extraction efficiency taken into account, the average partition rate for norbixin into whey across all trials was $10 \%$ (Table $1 ; P>0.05$ ). An average of $81 \%$ of norbixin added to milk was recovered in the cheese $(P>0.05)$. These values are contrary to the widely held belief that $20 \%$ of norbixin added to cheese milk ends up in the cheese whey (Barnicoat, 1950; Chapman et al., 1980).

More norbixin was lost during the fat-free cheese make procedure than the full-fat cheese procedure (12 vs. $7.6 \%$, respectively, Table $1 ; P<0.05)$. Norbixin loss was likely due to heat and light during cheese manufacture. It is well established that both light and heat have destructive effects on norbixin (de Oliveira and Rodriguez-Amaya, 2007) and these are the likely culprits of norbixin destruction during the cheese make procedure. The greater norbixin loss during fat-free cheese manufacture may be due to the lack of opacity in the fat-free whey due to lack of fat. Opacity in the whey, caused by fat, may protect norbixin from exposure to light, whereas the clearer fat-free whey has a greater portion of norbixin directly exposed to light during the cheese making process. The norbixin loss relationship between full-fat treatments was linear likely because the same proportion of norbixin is exposed to light during the cheese make procedure, irrespective of the total amount of norbixin added.

For experiment 2, homogenization of bixin into the milk caused initial colorant loss during the process. Because of this initial loss, the extraction efficiency of bixin from milk was not calculated. Norbixin and bixin levels were tested in both treatments to ensure an equal concentration of colorant in milk before cheese manufacture $(10.4 \mathrm{mg} / \mathrm{kg})$. A higher percentage of norbixin $(9.27 \%)$ compared with bixin $(1.30 \%)$ was recovered in unseparated whey $(P<0.05)$, concurrent with a higher recovery of bixin in cheese compared with norbixin $(94.5$ vs. $80 \%$, respectively; $P>0.05$ ). Results for norbixin (homogenized) recovery (extraction efficiency) were consistent with norbixin (unhomogenized) recovery in experiment 1 (89 vs. $88.7 \%$, respectively; $P>0.05$ ), indicating that homogenization did not affect partitioning of norbixin. Zhu and Damodaran (2012) suggested that annatto in Cheddar cheese whey was primarily associated with the milk fat globule membrane. Homogenization of milk reduces fat globules to a more uniform and smaller diameter, which creates a greater

Table 1. The percentage total recoverable norbixin partitioned into whey and cheese and the percentage total norbixin recovered by solvent extraction

\begin{tabular}{|c|c|c|c|c|c|}
\hline Treatment $^{1}$ & $\begin{array}{c}\text { Extraction } \\
\text { efficiency (\%) }\end{array}$ & $\begin{array}{l}\text { Norbixin } \\
\text { loss (mg) }\end{array}$ & $\begin{array}{l}\text { Norbixin } \\
\text { loss (\%) }\end{array}$ & $\begin{array}{c}\text { Norbixin } \\
\text { in whey }(\%)\end{array}$ & $\begin{array}{l}\text { Norbixin in } \\
\text { cheese }(\%)\end{array}$ \\
\hline Full-fat $1 / 2 \times$ & $89.54^{\mathrm{a}}$ & 4.8 & $7.44^{\mathrm{a}}$ & $9.39^{\mathrm{a}}$ & $83.17^{\mathrm{a}}$ \\
\hline Full-fat $1 \times$ & $89.26^{\mathrm{a}}$ & 10.01 & $7.76^{\mathrm{a}}$ & $11.48^{\mathrm{a}}$ & $80.76^{\mathrm{a}}$ \\
\hline Full-fat $2 \times$ & $88.62^{\mathrm{a}}$ & 19.44 & $7.54^{\mathrm{a}}$ & $10.44^{\mathrm{a}}$ & $82.02^{\mathrm{a}}$ \\
\hline Fat-free $1 \times$ & $88.18^{\mathrm{a}}$ & 12.92 & $11.96^{\mathrm{b}}$ & $11.85^{\mathrm{a}}$ & $76.18^{\mathrm{a}}$ \\
\hline
\end{tabular}

a,b Means in the same column that do not share a common superscript are different $(P<0.05)$.

${ }^{1}$ Comparisons were made between treatments full-fat $1 / 2 \times(7.5 \mathrm{~mL}$ of annatto $/ 455 \mathrm{~kg}$ of milk), full-fat $1 \times$ (15 mL of annatto/455 kg of milk), full-fat $2 \times(30 \mathrm{~mL}$ of annatto $/ 455 \mathrm{~kg}$ of milk), and fat-free $1 \times(15 \mathrm{~mL}$ of annatto/455 kg of milk). 
surface area of fat globules and supposedly would make it easier to bind with the colorant if the previous statement were true. The amounts of norbixin and bixin recovered from whey decreased after fat separation of whey (norbixin: $33.6 \%$; bixin: $66.7 \%$ ). The decrease was greater for bixin than for norbixin $(P<0.05)$, indicating a stronger affinity for bixin for the fat phase in liquid whey, as expected, because bixin is nonpolar (Bareth et al., 2002). The results were also consistent with the supposition of Zhu and Damodaran (2012) that, in solution, annatto is probably in the form of micelles dispersed in the aqueous medium - in this case, liquid cheese whey - and it would be more likely to be associated with the milk fat globule membrane. The results suggested that norbixin is only partially associated with fat globules because there was a decrease in norbixin in cheese whey from homogenized cheese milk after fat separation but no decrease compared with nonhomogenized cheese milk from experiment 1 .

\section{Color of Norbixin and Bixin in Whey and Cheese}

Whey from bixin cheese had a significant decrease in $\mathrm{b}^{*}$ value compared with whey from cheese with norbixin $(P<0.05)$ and was visibly lighter in color (results not shown). The $\mathrm{b}^{*}$ value is associated with blue and yellow, where a higher positive value represents a more yellow color. For $\mathrm{L}^{*}$ and a* values, unseparated liquids for all 3 treatments were not distinct from each other $(P>0.05)$, but they all had lower $\mathrm{L}^{*}$ and $\mathrm{a}^{*}$ values compared with the same separated liquid wheys $(P<$ $0.05)$, which also were not distinct from each other $(P$ $>0.05)$. The $\mathrm{L}^{*}$ value is associated with white and black color (the higher positive value represents whiter color) and $\mathrm{a}^{*}$ is associated with red and green color (the higher positive value represents redder color). As shown in Figure 1, bixin was successfully dispersed in cheese. When cheese with bixin was compared with cheese with norbixin alone, cheese with bixin had lower $\mathrm{L}^{*}$ and $\mathrm{b}^{*}$ values, but higher $\mathrm{a}^{*}$ values $(P<0.05)$, which indicated that cheese with bixin was more red and less yellow. Although a color difference was visually evident between bixin cheese and norbixin cheese (Figure 1), the concentration of bixin could be modified in future studies to more closely match the color visually.

In conclusion, the solvent extraction efficiency of norbixin from milk was not affected by norbixin levels or by fat content. In Cheddar cheese, a smaller proportion of the annatto added to the cheese milk was present in the cheese whey than was previously thought. Only norbixin loss during cheese manufacture was distinct between full-fat and fat-free cheeses. A higher percentage norbixin loss in fat-free cheese may be due to the loss of opacity due to a lack of fat, meaning that the
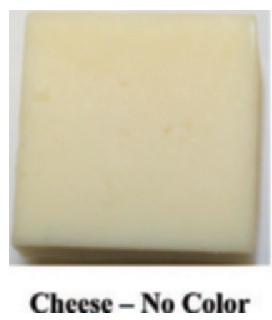

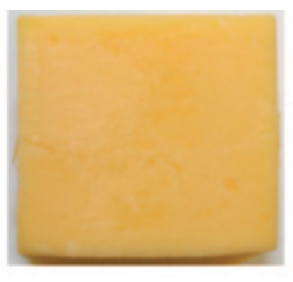

Cheese - Norbixin

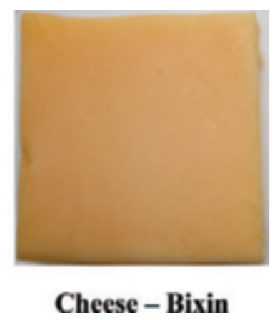

Figure 1. Cheese with and without norbixin at $15 \mathrm{~mL} / 454 \mathrm{~kg}$ of milk or bixin at $60 \mathrm{~mL} / 454 \mathrm{~kg}$ of milk. Color version available in the online PDF.

norbixin was exposed to light to a higher degree during fat-free cheese manufacture compared with the norbixin in manufacture of full-fat cheese. A lower percentage of bixin (10-fold) was partitioned into the whey during cheese manufacture compared with norbixin. This is likely due to a greater affinity for the nonpolar fat phase of the cheese milk, which largely remains in the cheese during whey drainage. These results indicate that bixin could be used as a viable alternative to norbixin in Cheddar cheese manufacture if the complications associated with stable suspension of bixin into the cheese milk without the need for homogenization can be resolved.

\section{ACKNOWLEDGMENTS}

Funding provided in part by the Dairy Research Institute (Rosemont, IL). The use of trade names does not imply endorsement nor lack of endorsement by those not mentioned.

\section{REFERENCES}

Bareth, A., W. Strohmar, and E. Kitzelman. 2002. HPLC and spectrophotometric determination of annatto in cheese. Eur. Food Res. Technol. 215:359-364.

Barnicoat, C. R. 1950. Reactions and properties of annatto as a cheese color. Part II. J. Dairy Res. 17:209-213.

Bouvier, F., O. Dogbo, and B. Camara. 2003. Biosynthesis of the food and cosmetic plant pigment bixin (annatto). Science 300:20892091.

Campbell, R. E., R. E. Miracle, and M. A. Drake. 2010. The impact of starter culture and annatto on the flavor and functionality of whey protein concentrate. J. Dairy Sci. 94:1185-1193.

Campbell, R. E., R. E. Miracle, and M. A. Drake. 2012. The use of lactoperoxidase for the bleaching of fluid whey. J. Dairy Sci. 95:2882-2890.

Carunchia Whetstine, M. E., J. D. Parker, M. A. Drake, and D. K Larick. 2003. Determining flavor and flavor variability in commercially produced liquid Cheddar whey. J. Dairy Sci. 86:439-448.

Chapman, H. R., S. Y. Thompson, and H. M. Slade. 1980. The use of carotenoid preparations for colouring Cheddar cheese. J. Soc. Dairy Technol. 33:162-164.

Cho, Y., C. A. Batt, and L. Sawyer. 1994. Probing the retinol-binding site of bovine $\beta$-lactoglobulin. J. Biol. Chem. 269:11102-11107.

Croissant, A. E., E. J. Kang, R. E. Campbell, E. Bastian, and M. A. Drake. 2009. The effect of bleaching agent on the flavor of liquid whey and whey protein concentrate. J. Dairy Sci. 92:5917-5927. 
de Oliveira, G. P. R., and D. B. Rodriguez-Amaya. 2007. Processed and prepared corn products as sources of lutein and zeaxanthin: Compositional variation in the food chain. J. Food Sci. 72:S079 S085.

Giuliano, G., C. Rosati, and P. M. Bramley. 2003. To dye or not to dye: Biochemistry of annatto unveiled. Trends Biotechnol. 21:513-516.

Govindarajan, S., and H. A. Morris. 1973. Pink discoloration in Cheddar cheese. J. Food Sci. 28:675-678.

Hammond, E. G., J. Chang, and G. W. Reinbold. 1975. Colorimetric method for residual annatto in dry whey. J. Dairy Sci. 58:13651366 .

Jervis, S. J., R. E. Campbell, K. Wohciechowski, M. A. Drake, and D. M. Barbano. 2012. Impact of bleaching whey on sensory and functional properties of $80 \%$ whey protein concentration. J. Dairy Sci. 95:2848-2862.

Kang, E. J., R. E. Campbell, E. Bastian, and M. A. Drake. 2010. Annatto usage and bleaching in dairy foods. J. Dairy Sci. 93:38913901 .

Lancaster, F. E., and J. F. Lawrence. 1995. Determination of annatto in high-fat dairy products, margarine and hard candy by solvent extraction followed by high-performance liquid chromatography. Food Addit. Contam. 12:9-19.

Li, X. E., R. E. Campbell, A. J. Fox, P. D. Gerard, and M. A. Drake. 2012. Influence of storage, heat treatment, and solids composition on the bleaching of whey with hydrogen peroxide. J. Food Sci. 77:C798-C804.

Listiyani, M. A. D., R. E. Campbell, R. E. Miracle, L. O. Dean, and M. A. Drake. 2011. Influence of bleaching on flavor of $34 \%$ whey protein concentrate and residual benzoic acid concentration in dried whey proteins. J. Dairy Sci. 94:4347-4359.

Listiyani, M. A. D., R. E. Campbell, R. E. Miracle, L. O. Dean, and M. A. Drake. 2012. Effect of temperature and bleaching agent on bleaching of liquid Cheddar whey. J. Dairy Sci. 95:36-49.
Lloyd, M. A., M. A. Drake, and P. D. Gerard. 2009. Flavor variability and flavor stability of U.S.-produced whole milk powder. J. Food Sci. 74:S334-S343.

Nair, S. S., V. V. Mistry, and K. R. Nauth. 2004. Reduction of salt $(\mathrm{NaCl})$ losses during the manufacture of Cheddar cheese. J. Dairy Sci. $87: 2831-2838$.

Nelson, B. K., and D. M. Barbano. 2004. Reduced-fat Cheddar cheese manufactured using a novel fat removal process. J. Dairy Sci. $87: 841-853$.

Scotter, M. 2009. The chemistry and analysis of annatto food colouring: A review. Food Addit. Contam. 26:1123-1145.

Scotter, M. J., L. Castle, C. A. Honeybone, and C. Nelson. 2002. Method development and analysis of retail foods for annatto food coloring material. Food Addit. Contam. 19:205-222.

US FDA (US Food and Drug Administration). 2011a. 21CFR184.1157 Benzoyl peroxide. Accessed Feb. 14, 2012. http://www.accessdata. fda.gov/scripts/cdrh/cfdocs/cfcfr/CFRSearch.cfm?fr $=184.1157$.

US FDA (US Food and Drug Administration). 2011b. 21CFR184.1366: Hydrogen peroxide. Accessed Feb. 14, 2012. http://www.accessdata. fda.gov/scripts/cdrh/cfdocs/cfcfr/CFRSearch.cfm?fr=184.1366.

US FDA (US Food and Drug Administration). 2011c. 21CFR101.62 Food Labeling. Accessed Mar. 30, 2012. http://www.accessdata. fda.gov/scripts/cdrh/cfdocs/cfcfr/CFRSearch.cfm?fr=101.62.

Whitson, M. E., R. E. Miracle, and M. A. Drake. 2010. Sensory characterization of chemical components responsible for cardboard flavor in whey protein. J. Sens. Stud. 25:616-636.

Wright, B. J., S. E. Zevchak, J. M. Wright, and M. A. Drake. 2009 The impact of agglomeration and storage on flavor and flavor stability of whey protein concentrate $80 \%$ and whey protein isolate. J. Food Sci. 74:S17-S29.

Zhu, D., and S. Damodaran. 2012. Short communication: Annatto in Cheddar cheese-derived whey protein concentrate is primarily associated with milk fat globule membrane. J. Dairy Sci. 95:614617. 